\title{
DIFFERENT APPROACH TO THE LACRIMAL SAC AREA*
}

BY

\author{
T. G. WYNNE PARRY \\ Bangor, North Wales
}

THE USUAL approach to the lacrimal sac and the area around is through the $\overrightarrow{0}$ standard curved incision, with the centre of the concavity about 2-3 mm. $\vec{\omega}$ from the inner margin of the inner canthus. It can be termed "adequate", although, to get a good view and to have freedom of manoeuvre, the incisiono. has often to be widely stretched in all directions. Even then, one is oftent working in a fairly deep cavity difficult to illuminate and the occasional haemorrhage makes matters worse.

For the past 18 months, I have been using a modification of this approach? which seems to me to give many advantages over the standard one.

The usual curved incision is made through the skin about 1 inch long and with the centre of the curve about $2 \mathrm{~mm}$. from the inner margin of the canthus. Frome each end of this skin incision and at right angles to it, two short incisions areo made which extend nasally for about half an inch (Fig. 1). The edges of the skino flap outlined are dissected loose and three single armed sutures of " 0 " silk ares inserted-one through each free corner, and one through the edge of the flap ato the middle. The sutures are left fairly long with the needles still attached and ao small clip is put on the two ends of each. The skin flap is then dissected up to the limit of the nasal incisions and the flap is turned over on to the bridge of theo nose, the weight of the three small clips keeping it well out of the way (Fig. 2).

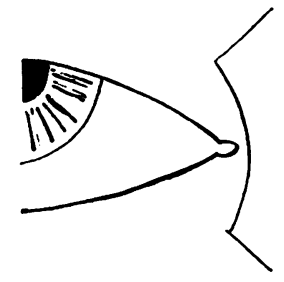

FIG. 1.-Incision.

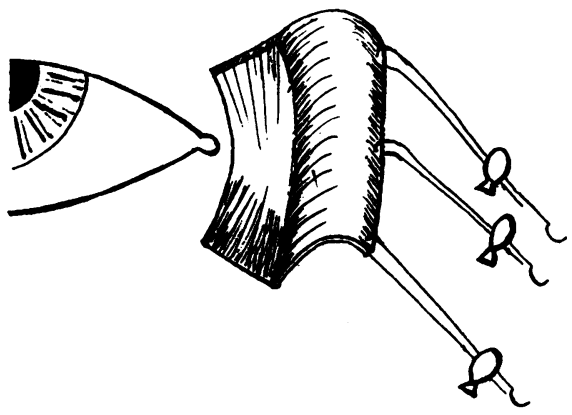

FIG. 2.-Flap of skin turned back and three sutures inserted. 
whole of the "lacrimal sac area" to be well seen and dealt with with freedom and ease and without the necessity for the usual retraction and stretching of the skin incision.

At the end of the operation, the three sutures are unclipped and inserted into their corresponding points on the outer lip of the curved incision, and further sutures can then be added between them. If necessary one or two fine catgut sutures can be placed in the muscle layer before the skin flap is replaced.

Little if any scar is left, the flap falling naturally into place without having been exposed to stretching.

It has been found that, although this method involves a little more work and slightly more suturing, the advantages of a full exposure and more working space amply compensate for these slight drawbacks. 